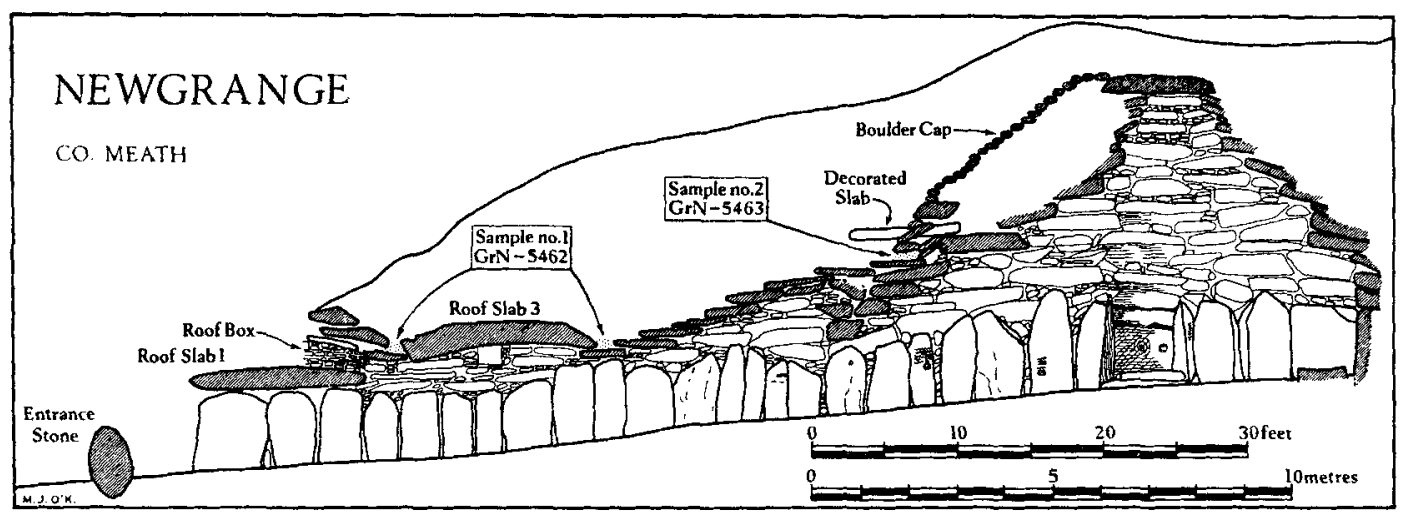

Fig. I. Section of Newgrange Passage Grave with positions of charcoal samples dated by CI4

tomb was being built, and since then it has lain covered by an undisturbed layer of cairn material more than $3 \mathrm{~m}$. thick. The burnt soil contained charcoal in fragments from small twigs, Sample no. I providing 10.3 grams and Sample no. 2 providing 50.8 grams. All of Sample no. I and 20 grams of no. 2 were sent to the Radio carbon laboratory in the Royal University at Groningen, Netherlands, and

\section{Statistics in Archaeology}

In the September 1968 issue of ANTIQUITY Colin Renfrew refers to Hole and Shaw's recent book on seriation [ $\mathrm{r}$ ] as 'the first monograph on the use of statistics in archaeology'. We feel that this is an opportunity to draw attention to a little-known monograph by the late Oliver Myers, entitled Some Applications of Statistics to Archaeology and published by the Government Press, Cairo, in 1950. Myers, whose pioneering work in the field has been too little recognized, would himself have dated the first monograph on statistics in archaeology to 1877 when Flinders Petrie published his Inductive Metrology.

Myers's monograph deals with three subjects. Two of these, the correlation between absolute frequencies of different artifact classes in different parts of the same site, and the effects of weathering on the hardness and size of potsherds, are at a basic observational level. The third is concerned with the problem posed thanks to Professors Waterbolk and Vogel we now have two dates-Newgrange no. I (GrN-5462) $255^{\circ} \pm 45 \mathrm{BC}$, and Newgrange no. $2(\mathrm{GrN}-5463) 2465 \pm 40 \mathrm{BC}$. Presumably the two may be put together to give a round figure date of $2500 \mathrm{BC}$, which makes the tomb perhaps half a millennium older than was thought possible even in fairly recent times. MICHAEL J. O'KELLY

by the fact that many Saharan surface sites contain the debris of culturally different occupations. Myers provided a system, based on a correlation between areal distribution, for obtaining, under favourable circumstances, valid culturally associated groups of artifacts. Among the techniques used and described are tests of differences between population means, correlation and the analysis of variance.

Among his other work were a neat demonstration of the extent and essential randomness of vertical transport of sherds in archaeological deposits and a seriation technique with a difference [2]. This relied, not on the difference between individual assemblages, but, after the manner of dendrochronology, on marrying up short stratigraphically sound sequences, to produce a long overall sequence. It was thus the patterns of change within each segment which were fundamental to the method, matching and calibration of one segment 


\section{ANTIQUITY}

against another being decided by a least squares criterion. This approach does not make the assumptions of Robinson and Brainerd [3] as to the pattern of cultural change, but simply assumes that that pattern is broadly similar over the material to be studied.

Needless to say Myers worked without benefit of computer, though not without benefit of expert statistical advice. His achievements may serve as a reminder that there is much statistical work to be done at levels far

\section{Kot Diji and Hissar III}

As far back as 1943 Stuart Piggott wrote, 'In any scheme of post-war archaeology in the East, the further elucidation of the Indian prehistoric sequence should be given an important place, not merely to establish this within India, but as a means whereby the stratigraphy and chronology of Iranian sites can be checked from the east no less than from the west' (1943, r82).

The object of this note is to draw attention to a close parallel between a design-motif from Kot Diji and an analogous object from Hissar IIIc, and incidentally to suggest a terminus $a$ $q u o$ for the latter, on the strength of the $\mathrm{C}_{4}$ dates for the various stratified levels of the former (FIG. 1).

The excavations of Kot Diji, Khairpur Division, West Pakistan, brought to light a unique design, painted in black on the dark brown slip over a red background, of a vessel with a very short neck, bulging body and a flat base. It is said to represent a horned deity (Khan, r965). Within the stylized bucranian horns on either side is seen a six-petalled flower outlined with black and filled with white. The gracefully curved horns are painted in black, but additionally these bear, at regular intervals, an oval, leaf-like motif done in white. From the junction of the horns seems to 'hang' down an elongated human head, its chin and cheeks shown in black dots, the low forehead, and the upper part of the long drooping ears in solid black.

The vessel was found intact in layer $3 \mathrm{~A}$, and is fairly large $(33 \mathrm{~cm}$. broad, and $20 \cdot 3 \mathrm{~cm}$. total more fundamental than that of interpretative seriation and that for a great deal of quantitative work in archaeology a computer is a dispensable luxury.

THURSTAN SHAW and S. G. H. DANIELS

[r] F. Hole and M. Shaw, Computer Analysis of Chronological Seriation (Houston 1968).

[2] O. H. Myers, "Abka re-excavated', Kush, 6, 1958.

[3] W. S. Robinson and G. W. Brainerd, 'A method for chronologically ordering archaeological deposits', American Antiquity, xvi, I951, 293.

height). Stratigraphically it is assigned to the late Kot Diji culture, from which was also found a slightly smaller vessel with the typical fish-scale design (Khan, I965, 59, fig. I6, pl. XVII). Though Dr Khan assigns both vessels to the Kot Diji Culture, according to his own statement (p. 15), layer 3 is Harappan and layer $3 \mathrm{~A}$ transitional, so that both these layers could well be Harappan because in the latter $(3 \mathrm{~A})$ were present both Harappan and pre-Harappan (or Kot Diji) cultural elements.

This little detail about the stratigraphical position of the vessel is necessary when we discuss the ancestry of the design. For it is partly Iranian and partly Indian (Harappan).

The immediate ancestor of this human head and bucranium with flowers set in each of its wings seems to be Iranian, particularly Hissar IIIc, where five gold sheets with a mouflon (wild mountain sheep of southern Europe) according to Schmidt (1937), or ibex (Gordon, I961), were found in a hoard. The horn sheets bore additionally seven pairs of perforations which pierced the long, coiled horns and the beard of the animal so that this gold ornament - probably with some ritualistic significancecould be stitched on cloth or leather as inferred by Schmidt ( $937, x 89$ ).

For the inset flower motif we have to go to earlier Iranian periods such as Hissar IB (Schmidt, 1937, pl. v), and Sialk (Ghirshman, 1939) where, within the horns curving upwards, and forming almost a circle, are found one or two flowers. So long as the motif remained in Iran, the original animal head 